\title{
Preventing intravenous bag contamination
}

\author{
Christopher L. Pysyk, MD, FRCPC
}

Received: 25 November 2016/ Accepted: 12 December 2016/Published online: 27 December 2016

(C) Canadian Anesthesiologists' Society 2016

\section{To the Editor,}

With the heightened concern of surgical-site infections and growing evidence of omnipresent contamination of the anesthesia environment, ${ }^{1}$ an unrecognized loss of sterility may be anesthesia's dirty little secret. When stopping a partially completed intravenous (IV) infusion and swapping it for another (e.g., stopping a crystalloid infusion to administer an antibiotic-containing solution), a frequent sequence of events includes the following: 1) clamping the exit limb of the IV bag; 2) removing the IV tubing from the now clamped bag; 3) inserting the IV tubing into the desired fluid (new) IV bag.

The clamp is applied to prevent leakage of the formerly infused fluid, thus permitting future use and minimizing any waste of the remaining solution. Of note, the clamped IV bag frequently remains hanging on the IV pole with the exposed exit limb in close proximity to items of questionable sterility (e.g., IV pole surface, clips/clamps that support the surgical drapes, the handled - now unsterile $^{2}-$ portion of the surgical drapes).

To minimize the risk of contamination, one can insert a sterile cannula cover of a blunt needle (Figure) into the IV fluid exit limb when clamping and disconnecting a fluid bag from the IV tubing. The aforementioned clamp and

C. L. Pysyk, MD, FRCPC ( $\square)$

Department of Anesthesiology and Pain Medicine, The Ottawa Hospital, Ottawa, ON, Canada

e-mail: cpysyk@toh.on.ca

\section{L. Pysyk, MD, FRCPC}

Faculty of Medicine, Department of Anesthesiology,

University of Ottawa, Ottawa, ON, Canada

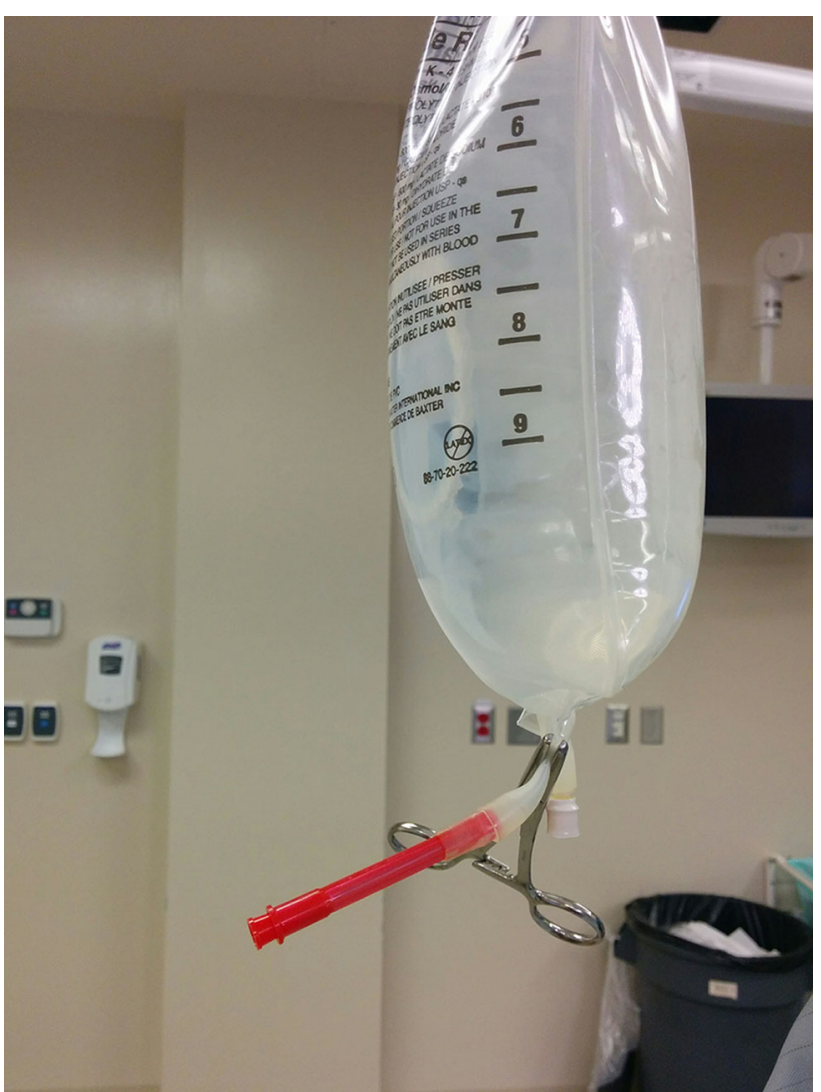

Figure Cannula cover for the exit limb of the clamped intravenous bag

covered cannula technique is also less resource costly than starting a secondary IV infusion set.

Conflicts of interest None declared.

Editorial responsibility This submission was handled by Dr. Philip M. Jones, Associate Editor, Canadian Journal of Anesthesia. 


\section{References}

1. Loftus $R W$, Brown JR, Koff MD, et al. Multiple reservoirs contribute to intraoperative bacterial transmission. Anesth Analg 2012; 114: 1236-48.
2. Loftus RW, Muffly MK, Brown JR, et al. Hand contamination of anesthesia providers is an important risk factor for intraoperative bacterial transmission. Anesth Analg 2011; 112: 98-105. 